\title{
Aeration Factor Used To Design The Container Type of Biopile Systems for Small-Scale Petroleum-Contaminated Soil Projects
}

\author{
Hyun-Gyu Jung* \\ Dept. of Environ. Eng. Graduate School. Kwangwoon Univ. Seoul Korea
}

\begin{abstract}
Biopiles which offer the potential forcost-effective treatment of contaminated soils are above-ground, engineered systems that use oxygen to stimulate the growth and reproduction of aerobic bacteria for degradation of the petroleum constituents adsorbed to soil in excavated soils. This technology involves heaping contaminated soils into piles and stimulating aerobic microbial activity within the soils through the aeration and/or addition of minerals, nutrients, and moisture. Inside the biopile, microbially mediated reactions by blowing or extracting air through the pipes can enhance degradation of the organic contaminants. The influence of a aeration system on the biopile performance was investigated. Air pressure made to compare the efficiency of suction in the pipes showed that there were slightly significant difference between the two piles in the total amount of TPH biodegradation. The normalised degradation rate was, however, considerably higher in the aeration system than in the normal system without aeration, suggesting that the vertical venting method may have improved the efficiency of the biological reactions in the pile.
\end{abstract}

Key words: Biopile, Air Permeability, Degradation, Petroleum

\section{Introduction}

Biopiles, like landfarms, have been proven effective in reducing concentrations of nearly all the constituents of petroleum products typically found at underground storage tank sites because biopile systems can be completed in a relatively short time (3 to 6 months) to remediate the contaminated soils. Biopile technology which operate effectively in temperate climates but can be operated in colder climates by introducing warm air through the aeration process involves forming petroleum-contaminated soils into piles or cells above ground and stimulating aerobic microbial activity which can be enhanced by adding moisture and nutrients such as nitrogen and phosphorus within the soils through aeration (Norris et al., 1994).

The biopile must be adequately aerated to support efficient degradation of contaminants by microorganisms. Biopiles in which a perforated piping network installed above the base is connected to a blower that facilitates the aeration of the pile typically are constructed on an impermeable base to reduce the potential migration of

\footnotetext{
Received : April 5. 2011 Accepted : April 12. 2011

*Corresponding author : Phone: +82234634616

E-mail: yemaek12g@naver.com
}

leachate to the subsurface environment.

The function and performance of a biopile are affected by interacting physical and biological processes including transport of oxygen, moisture and heat due to airflow and diffusion, consumption of oxygen and water by microorganisms and heat generated by bioreactions $(\mathrm{Li}$ et al., 2004). Of all the metabolic factors, oxygen is the most important, so efficient aeration is essential to biopile success.

Both active and passive air supply systems have been used successfully in the biopile systems (Brown and Cartwright, 1990; Kamnikar, 1992). The simplest method of pile aeration is a passive system that reduces not only capital and operating costs but also the potential for drying the pile because no blower is required and the airflow rate is low. However, active aeration is preferred despite the lower cost for passive aeration systems, because it gives more complete and more controllable airflow that speeds bioremediation in the pile. Typically, airflow rates through the pile to reduce the vapor emissions and prevent excess volatilization of hydrocarbons from the pile are just great enough to keep the soil above oxygen-limiting conditions.

However, overly stimulated airflow will not necessarily lead to improved biodegradation in conditions where 
the ambient temperature is less than that needed for optimal biodegradation within the pile. This approach to design the container type of mobile biopile systems for small-scale petroleum-contaminated soil projects is focused on air permeability in order to optimize the remediation system, one must understand how the increased airflow will change the internal moisture content and temperature of the pile.

\section{Theory}

The air permeability of a porous medium is one of the most important parameters controlling gas transport. Knowledge about gas transport in soil and other porous media is useful and important when, for instance, estimating contaminant transport at polluted soil sites, designing soil vapor extraction systems for remediation, estimating landfi 11 gas emissions to the atmosphere at old landfi 1ls, estimating aeration rates in agricultural soils, or designing biofi lters for air cleaning. Air permeability further depends very strongly on the pore structure and water content of the medium (Poulsen, 2008).

Inside the biopile, microbially mediated reactions result in degradation of the organic contaminants. By suitable enhancement of the conditions within the biopiles, degradation rates and the degree of degradation can be increased. In particular, natural and forced aeration can be introduced to enhance soil venting in order to provide oxygen for the bioreaction in the pile.

Air permeability is defined as the ability of soil to transmit air through interconnected air-filled pores under an imposed air pressure gradient. Like hydraulic conductivity, air permeability is a function of volumetric water content, porosity, pore size distribution, and pore geometry (Roseberg and McCoy, 1990). Air permeability estimates are required to predict or evaluate system performance using the available analytical and numerical models. Indirect, laboratory, and field methods for estimating air permeability can be presented as follows.

Air permeability can be estimated as a function of saturated hydraulic conductivity. Intrinsic permeability can be obtained from the definition of saturated hydraulic conductivity as

$$
k_{i}=\frac{k \cdot \mu}{\rho \cdot g}
$$

where $k_{i}$ is intrinsic permeability $\left(\mathrm{L}^{2}\right), \mathrm{K}$ is saturated hydraulic conductivity $\left(\mathrm{L} \mathrm{T}^{-1}\right), \mu$ is dynamic viscosity of water $\left(\mathrm{M} \mathrm{L}^{-1} \mathrm{~T}^{-1}\right), \rho$ is density of water $\left(\mathrm{M} \mathrm{L}^{-3}\right)$, and $\mathrm{g}$ is gravitational constant $\left(\mathrm{L} \mathrm{T}^{-2}\right)$. And the relationship between air permeability and intrinsic permeability is typically expressed as

$$
\mathrm{k}=k_{i} * k_{r a}
$$

where $k$ is air permeability, $k_{i}$ is intrinsic permeability, and $k_{r a}$ is relative permeability to air.

Also Corey (1986) developed the relative permeability to air using Burdine's solution in conjunction with the Brooks-Corey pressure-saturation relation (Brooks and Corey, 1964).

$$
k_{r a}=\left(1-S_{e}\right)\left(1-S_{e}^{\left(\frac{2+\lambda}{\lambda}\right)}\right)
$$

where $S_{e}$ is effective water saturation and $\lambda$ is BrooksCorey pore size distribution.

And effective water saturation Se is further defined as Eq [4]

$$
S_{e}=\frac{S_{w}-S_{r}}{1-S_{r}}
$$

where $S_{w}$ is water saturation and $S_{r}$ is residual water saturation.

Massmann (1989) reported that air permeability could be roughly estimated as a function of the average pore radius from grain size analyses performed on soil samples using the following relationship

$$
k_{i}=0.125 r^{2}
$$

$k_{i}$ is intrinsic permeability (darcies) and $r$ is characteristic pore radius $\left(\mathrm{mm},=c D_{15}\right)$. Herewith $\mathrm{c}$ is empirical constant approximately equal to 0.1 for sand and gravel, and $D_{15}$ is grain size for which 15 percent by weight of particles are smaller (mm).

However, the airflow in the biopile is assumed to be two dimensional and the geometry of the pile is approximated by a half circle as shown Fig. 1 (Li et al., 2004). Because the pressure gradients are relatively low, the air compressibility is neglected. Flow in the interior of the biopile is driven by the wind-induced 
pressure difference around it. Based on the potential flow theory, the pressure difference can be quantified as Kundu and Cohen (2001):

$$
2\left(p-p_{\infty}\right)=\rho U^{2}\left(1-4 \sin ^{2} \theta\right)
$$

where $p_{\infty}$ is the ambient pressure (at a distance from the pile), $U$ is the wind speed, $p$ is the pressure on the surface of pile $(\mathrm{r}=\mathrm{R})$, is the air density and is the angle shown in Fig. 1.

Li et al. (2004) figured out that the pressure inside the pipe for vertical venting will be lowered and remains a constant for a given wind speed. The boundary condition at the pipe is therefore prescribed by a constant. To derive the analytical solution of the airflow for this case, Li et al. (2004) used the following conformal mapping.

$$
\eta=\frac{i\left(w^{2}-2 w-1\right)}{w^{2}+2 w-1}
$$

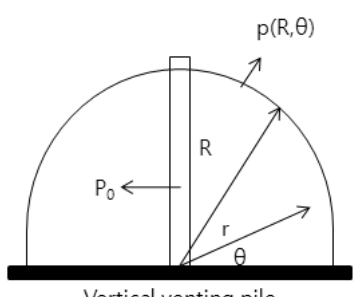

Vertical venting pile

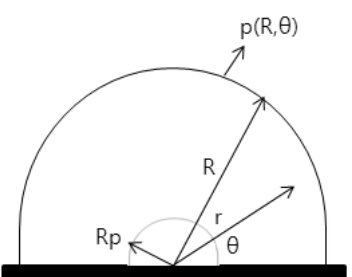

Horizontal venting pile

Fig. 1. Configuration of the pressure conditions at the boundaries of biopiles modelled as half circles as described by Kundu and Cohen (2001). $r$ is radial coordinate (m), $\mathbf{R}$ is radius of the pile $(\mathrm{m}), \theta$ is inclination angle from the ground (Rad).

\section{Material and Methods}

To compare the influence of the two types of aeration system on the biodegradation process, two biopiles were constructed, one with a standard passive aeration and the other with the vertically vented system. The contaminated soil was piled approximately $1 \mathrm{~m}$ high, $1 \mathrm{~m}$ wide and $2 \mathrm{~m}$ long. Two perforated polyethylene pipes (land drain, $140 \mathrm{~mm}$ in diameter) were placed in the middle of one pile. Soil hydrocarbon concentrations contaminated with diesel were adjusted to $25,000 \mathrm{ppm}$.

Soil sampling was made on days 0 (initial conditions), 3, 7, 14, 21 and 30. Each time, three soil samples per pile were taken from three different, representative locations in order to determine the overall behaviour/properties of the pile. Samples collected on days 0 and 30 were taken for further analysis by GC-FID (Hewlett Packard HP5890 gas chromatography with a flame ionization detector). A 30-m, HP-5 column with $0.32 \mathrm{~mm}$ inside diameter and $0.25-\mathrm{mm}$ film thickness was used to effect separation.

\section{Results and Discussions}

The reduction of hydrocarbons as diesel in normal and aerated piles is shown in Table 1. The overall trend of the hydrocarbon reduction in an aerated pile seems to be exponential, i.e., first-order kinetics.

To have a consistent comparison of the biodegradation between the two piles, the percentage of degradation was calculated (Fig. 2). Towards the end of the experiment the percentage of hydrocarbon degradation was higher in the aerated pile A than in the normal pile.

The trend displayed in Fig. 3 suggests that the biodegradation reaction in the piles can be described

\begin{tabular}{|c|c|c|c|c|}
\hline \multirow{2}{*}{ Day } & \multicolumn{2}{|c|}{ Normal } & \multicolumn{2}{|c|}{ Aerated } \\
\hline & TPH & Variability & TPH & Variability \\
\hline & $m g \mathrm{~kg}^{-1}$ & $\%$ & $\mathrm{mg} \mathrm{kg}^{-1}$ & $\%$ \\
\hline 0 & 25,121 & 22.4 & 25,004 & 6.2 \\
\hline 3 & 24,889 & 18.6 & 20,487 & 3.8 \\
\hline 7 & 22,145 & 20.6 & 17,024 & 4.2 \\
\hline 14 & 20,147 & 14.5 & 14,471 & 2.1 \\
\hline 21 & 18,654 & 18.2 & 11,334 & 5.8 \\
\hline 30 & 16,247 & 16.3 & 9,878 & 7.4 \\
\hline
\end{tabular}

Table 1. Temporal variations of the oil content in the piles. 


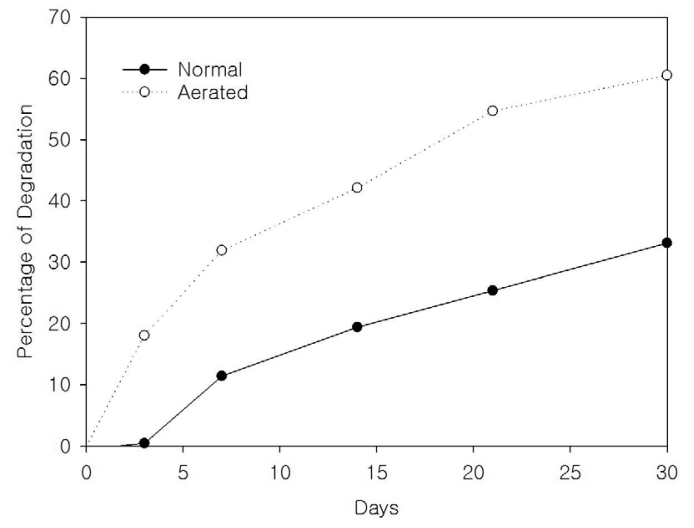

Fig. 2. Percentage biodegradation for the nomal and the aerated biopile

by the first order kinetics, i.e., for the normal and the aerated piles.

$$
\begin{aligned}
& \frac{d H}{d t}=-b H \\
& H=H_{o} \operatorname{Exp}(-b t)
\end{aligned}
$$

where $\mathrm{H}$ is the hydrocarbon concentration and $\mathrm{b}$ is the degradation rate. The solution of $\mathrm{H}$ is thus represented by $\mathrm{Eq}[8]$.

A weighted regression method was applied to fit the data to Eq. (8) in order to determine the degradation rates for both piles. This method took into account the variability of the data points. The fitting weighs more the data points with low variability. The results are shown in Figs. 3 for both piles. The results of the weighted regression limit were used to calculate the confidence limits of the slopes:

The results were 0.0314 and 0.811 per day for the normal pile and the aerated pile, respectively. Although the degradation rate in the aerated pile was relatively higher than that of the normal pile, the difference between the two was large and statistically slightly significant.

\section{Conclusions}

The purpose of this study was to test an aeration system for biopiles of diesel-contaminated soils by comparison with a system without aeration. The results of TPH degradation were conclusive regarding the effectiveness of the aeration system in improving the performance of biopiles. The degradation rates obtained from the zeroorder and first-order models indicate that the new system might have increased the efficiency of the bioreaction

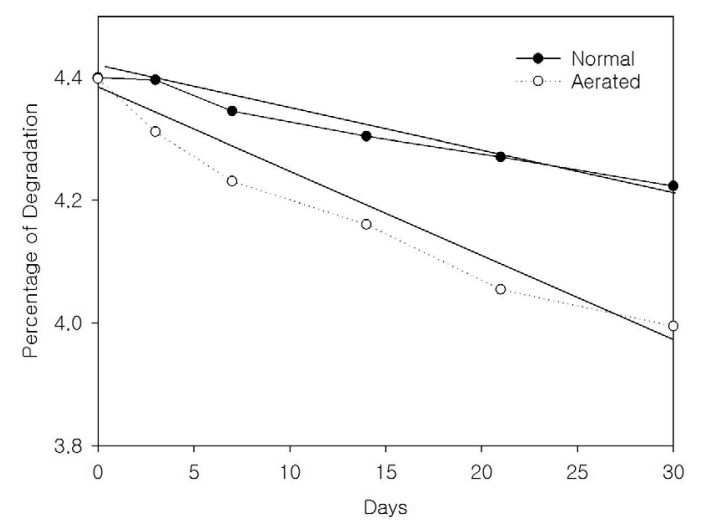

Fig. 3. Logarithm (base 10) of the TPH concentration in the pile and the regression results for the normal and the aerated.

in the pile. Further studies need to be carried out to quantify how the airflow affects the moisture content in the pile. An ideal aeration system must reach an optimal balance

\section{Acknowledgment}

This study was supported by grant of Korea Ministry of Environment as "Advanced ET Education Center for Soil and Groundwater Remediation".

\section{Reference}

Brooks, R.H. and A.T. Corey. 1964. Hydraulic properties of porous medium. SCSU (Fort Collins). Hydrology paper. 3.

Brown, R.A. and R.T. Cartwright. 1990. Biotreat sludges and soils. Hydrocarbon processing. 88:93-97.

Corey, A.T. 1986. Mechanics of Immiscible Fluids in Porous Media. In: Water Resources, Littleton, CO. p. 259.

Li, L., C.J. Cunningham, V. Pas, J.C. Philp, D.A. Barry, and P. Anderson. 2004. Field trial of a new aeration system for enhancing biodegradation in a biopile. Waste Management 24:127-137.

Massman, J.W. 1989. Applying groundwater flow models in vapor extraction system design. Journal of Environmental Engineering. 115:129-149.

Norris, R.D., R.E. Hinchee, R.A. Brown, P.L. McCarty, L. Semprini, J.T. Wilson, D.H. Kampbell, M. Reinhard, E.J. Bower, R.C. Borden, T.M. Vogel, J.M. Thomas, and C.H. Ward. 1994. Handbook of Bioremediation. Boca Raton, FL:CRC Press.

Poulsen, T.G., H. Blendstrup, and Per Schjønning. 2008. Air Permeability in Repacked porous media with variable structureforming Potential. Vadose Zone 7:1139-1143.

Roseberg, R.J. and E.L. McCoy. 1990. Measurement of soil macropore air permeability. Soil Sci. Soc. Am. J. 54:969-974. 